\title{
STUDY IN MECHANICAL FAULT ELEMENT THERMOGRAPHY THROUGH THE MACHINE: The case of deep groove ball bearings of a career without screen.
}

\author{
by Francisca C. da Silva ${ }^{1}$, Juscelino F. Maribondo², Antônio S. Almeida ${ }^{3}$, Tadeu C. da Silva ${ }^{4}$, Richard Senko ${ }^{5}$ \\ 12 Federal Univ. of Campina Grande, PPGEM, Campina Grande, PB, Brasil, ${ }^{1}$ cibeleproj@hotmail.com \\ 2juscelinodefarias@oi.com.br, 3antonio.almeida@ufcg.edu.br \\ 4Univ. of Brasilia, Mechanical Engineering Dept., FT, 70910-900, Brasilia, DF, Brazil, tcastro@unb.br \\ ${ }_{5}$ Federal Univ. of Paraíba - UFPB, PPGEM, João Pessoa, PB, Brasil, senko.richard@gmail.com
}

\begin{abstract}
The objective of this study is to analyze the possibility of Thermography aid predictive maintenance to detect mechanical failures in rigid a career unshielded ball bearings. Therefore, eight samples were prepared containing various flaws in the tracks of the inner and outer rings of the bearings. Subsequently, each bearing sample was coupled to a bearing with the shaft and motor, positioned on the inertial table. Then the qualitative and quantitative thermography measurement probes associated with the collection of mechanical vibration data were prepared. The results show that it is possible to see the temperature variations associated with mechanical failures introduced compared to records timefrequency vibration spectrum.
\end{abstract}

\section{Introduction}

For the production in industries achieve their goals if the monitoring of various activities is necessary, including, corrective, preventive maintenance. Such maintenance are responsible for maintaining the industrial park in good working order and, therefore, production within expected parameters [1], [2]. The machines, in turn, must operate reliably for such production are achieved. increases in speed, power and pressure, for example, wear requires the machine elements arising from relative movements of one component relative to another due to friction and vibration generating heat which causes usually wear and failure [3], [4], [5], [7]. Detect and diagnose prematurely these events allows managers to use the means of production more efficiently and effectively.

One of the items that can help maintainers with fault detection is rolling, as they are responsible for the systems. Among the information that they can send to those responsible for maintenance are increasing temperature, increasing noise and mechanical vibration. All these aspects are related to an anomaly of poor lubrication, excessive loads and / or end of life.

One of the most common wear resulting from bearings are the flaws in the raceways of inner ring and / or outer ring [4], [13]. This is because of mechanical shock between the balls and raceways, which rub during the kinetic movement and consequently, there is the thermal power generation. The incident heat in the friction region propagates continuously on the track surface, changing the thermomechanical properties of the material causing the bearing anomalies appearance.

The heat emitted by the friction of the bearing components can be realized through a technique called thermography [7], [18]. The technique senses the temperature variations across the temperature gradient on the surface of the material, these information records are made by thermographic cameras and thermal imagers measuring infrared radiation, and provides a thermogram for measuring thermal distribution on the surface of the mechanical element analyzed.

Given the above this work seeks to answer the following questions: Can this technique be used to detect mechanical failures in rigid bearing a career unshielded balls? What variables should be manipulated to obtain the data? And as proof that the data correspond to reality? Therefore, it elaborated laboratory experiments with samples of bearings with the introduction of mechanical defects in its internal and external cues for later analysis of their behavior by means of thermography and vibration analysis.

\section{THE STUDY: The thermography and vibration analysis.}

The thermographic analysis and vibration analysis are defined as non-destructible test techniques used in predictive maintenance. They are techniques different applications that can help identify mechanical failures. Thermography captures the emission of electromagnetic waves within the infrared spectrum. It stands out for direct contact not need the equipment to be analyzed. This makes it a safe technique to maintain operator [6],[7]. Through the thermal variation of the surface of the object under examination and visualization of the thermographic camera of the color palette it is possible to perform the thermal analysis and therefore analyze possible malfunctions of equipment in study.

Since the vibration analysis is said to be a process by which faults in components of a mobile equipment, are discovered by the variation rate of the dynamic forces generated, which are registered reading of the spectral frequency and amplitude of the defect [NBR 10273:2013]. It is a major techniques applied to rotating elements.

In the development of this work was made use of both techniques in order to analyze and confirm that thermography can be used to diagnose failures in rotating elements, in this case, hard bearing a ball career, unshielded. The choice of such a machine element was due its wide use in the industrial environment. 
In this context, flaws were introduced in their internal cues to create anomalies that are observed in the field and from this point to make use of the techniques mentioned above to detect (thermography) and confirm (vibration analysis), validating the experiments. The hypothesis worked is that the occurrence of a failure in the bearing race will cause impacts that will generate heat and noise that can be recorded by thermography and analysis of vibrations, respectively. For vibration analysis is made use of Eq. (1) and (2) for modeling the faults in the inner race and outer race, respectively.

$$
\begin{aligned}
D P F I & =\frac{n \cdot f r}{2}\left(1+\frac{B}{D P} \cos \theta\right) \\
D P F O & =\frac{n . f r}{2}\left(1-\frac{B}{D P} \cos \theta\right)
\end{aligned}
$$

Wherever: $\mathrm{DP}=$ diâmetro "pitch", $\mathrm{B}=$ Ball diameter, $\mathrm{fr}=$ rotation frequency, $\theta=$ contact angle, $\mathrm{n}=$ number of balls and the term DPFI e BPFO (are the fault characteristic frequencies).

The vibration makes use of the frequency range and their repetitions to diagnose the fault, in case the friction caused by metal-to-metal contact generated by rolling into balls in the defective track. This contact generates energy that accumulate with movement and end up helping to diagnose it. Fig. 1 shows an example of a failure caused by inadequate lubrication and forms planning to detect it.

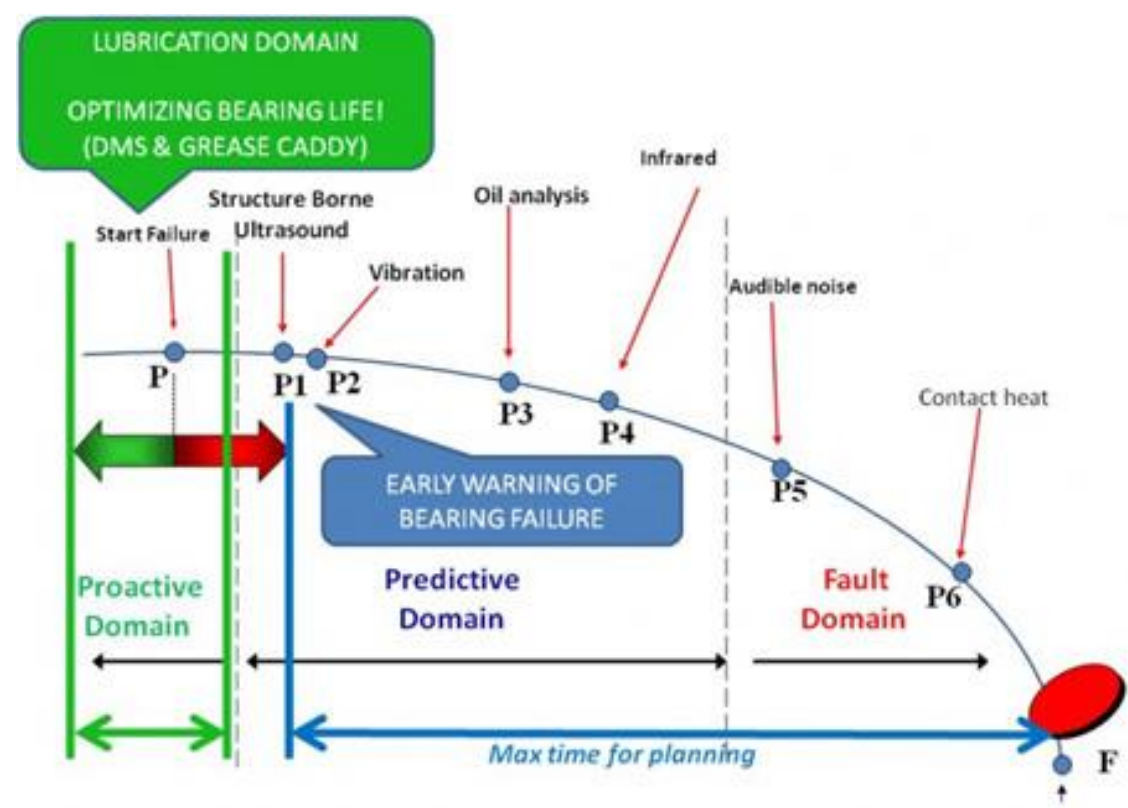

Fig. 1. Appearance and behavior of a failure and the means to plan their diagnosis. Source - EU Systems.

In Figure 1 to realize the best times to make use of vibration analysis (point P2) and Thermography (point P4). Regular use of these techniques in the field can contribute to reducing costs for corrective maintenance due to the early diagnosis of failure. For example, when a fault is present at an early time, the energy generated by the fault produces electromagnetic waves by thermal radiation. The propagation does not depend on the presence of a physical medium [13]. It is by means of a set of designated particle: photons or quanta and this end to facilitate its extraction and hence its analysis and diagnosis, reducing maintenance costs. But in order to interpret them becomes important to know and manipulate certain variables, namely: wavelength, emissivity, reflected temperature, relative humidity, air velocity, air temperature, camera distance to the object of study, focus , framing and characteristics of the thermographic camera [6], [18]. These variables help to get a good thermogram and facilitate its interpretation. Another important aspect is to determine whether the information in the thermograms should be qualitative or quantitative. Together, in the form of data, such variables help to make a proper diagnosis the technician responsible for the diagnosis of failure.

\subsection{The study element: Rolling}

Authors such as [4], [7]; [17] It is agreed that the bearings are among the most important components of a machine. In impel the transient elements bearings support transmission of movements, misalignments, high loads and mechanical forces, which in excess contribute to thermomechanical changes in the material. To resist such efforts, the company employing materials with high hardness characteristics and high resistance to wear. For example, make use of martensitic steel AISI 440C and stainless steel. On the other hand, also seek the best properties of these materials to facilitate the manufacturing of bearings to increase its useful life. Another important aspect to highlight is that the bearings are made in extreme thermal diffusivity materials and tend to have their resistance changes with temperature, like the steel, which facilitates the spread of heat due to their highly conductive properties. [14] 
The high thermal conductivity of this material during operation can be perceived through the heat emission from the surface. The increase and reduction of this heat over time, reduces the strength of the material, thus affecting its mechanical properties [15], [18]. Given the above, such thermal emission seen in the bearing can provide a variety of information, including the occurrence of type anomalies, mechanical failures surveyed in this work.

For example, if a mechanical system in operation heats up too early there is instability that is necessary to quantify and qualify it. In the case of heating the contact bearing surface and the track with adjacent layers other internal components of the bearing can nuclear cracks, which correspond to cyclic shear stress common in these types of machine elements [14] e [18].

However, one must realize situations which actually contribute to the emergence of these shortcomings, namely maintenance failure, cyclical loading system, excess load for static or dynamic rolling, lubrication failure or impurities inside the bearings. All these factors contribute to the appearance of defects and therefore overheating, which may cause flaws [4], [18], [19] e [16]. But even when the need for maintenance is present Thermography does not require interruption of normal operation, or as little, it is necessary physical contact between the inspector and the object to be analyzed, that is a positive point for the application this technique because it can reduce the time for diagnosis of the failure and maintenance costs involved for diagnosis.

\section{Methodology}

The methodology used in the development of this work is presented in Figure 2, the Flowchart -1 .

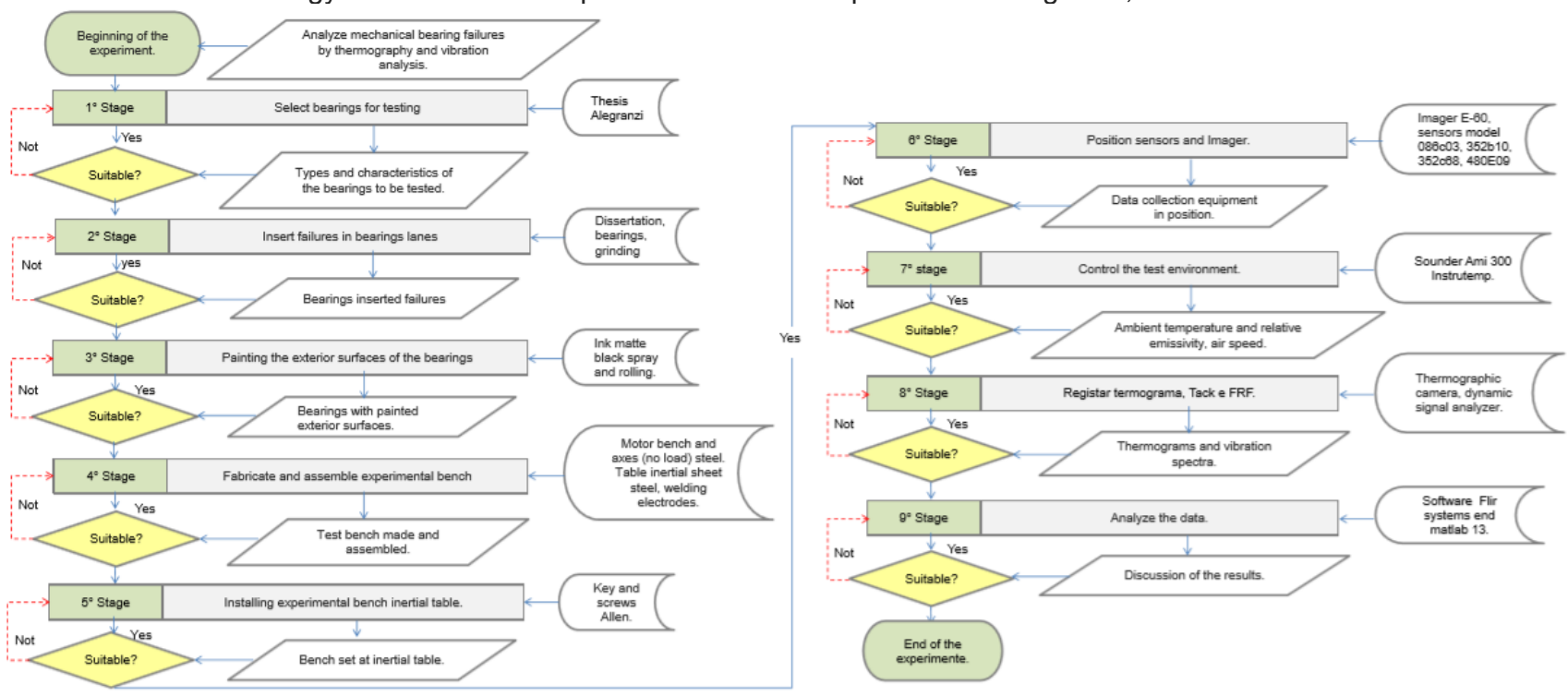

Fig. 2. Flowchart of the Methodology.

With an established need nine activities were developed called steps. Each step were set the expected results and the development of each stage were described the means to carry them out (see Fig.2). With respect to Step 1 designed to select the bearings for the laboratory testing was done using the research work Alegranzi [3]. The intention was to use this work as a reference to discuss the results of this new experiment presented in this research. At work [3] it makes use of vibration analysis as a diagnostic technique while this research is done using thermography. It is compared to the end that was detected by vibration analysis can be detected by means of thermography technique.

The samples were thus prepared: Brand Bearings NSK C4DDUC4 [20]. Inserted holes in inner races called c and the called external cues A1, A2, A3 e A4. The length of the failures were thus established: $3.5 \mathrm{~mm}, 3.0 \mathrm{~mm}, 2.0 \mathrm{~mm}$ and $1.0 \mathrm{~mm}$ respectively. The outer faces of the bearings were painted with paint matte black oil brand Sherwin-Willians. Subsequently he fashioned up and set up an experimental table steel measuring $530 \mathrm{~mm}$ wide by $250 \mathrm{~mm}$ deep by $53 \mathrm{~mm}$ in height for receiving the components of the experiment.

Then, each sample was individually inserted in the housing connected to $1 / 2 \mathrm{hp}$ induction motor $1740 \mathrm{rpm}$ and 60 $\mathrm{Hz}$ by means of a shaft, which were assembled after positioned on the inertial table. Held this assembly coupled to the sensors (accelerometers) in the bearing $Y$ and $Z$ positions and thermally insulated by a bearing housing with polystyrene painted matt black internally and externally enveloped by aluminum foil. Vide Fig. 3.

For thermal image recording used the Imager E-60 Flir Systems with reading in the spectral range 7.5 a13 $\mu \mathrm{m}$ a focal length of $400 \mathrm{~mm}$. Monitoring of images was carried out over a total time 30 minutes. After stabilizing the system every 5 minutes had become a record thermographic. 

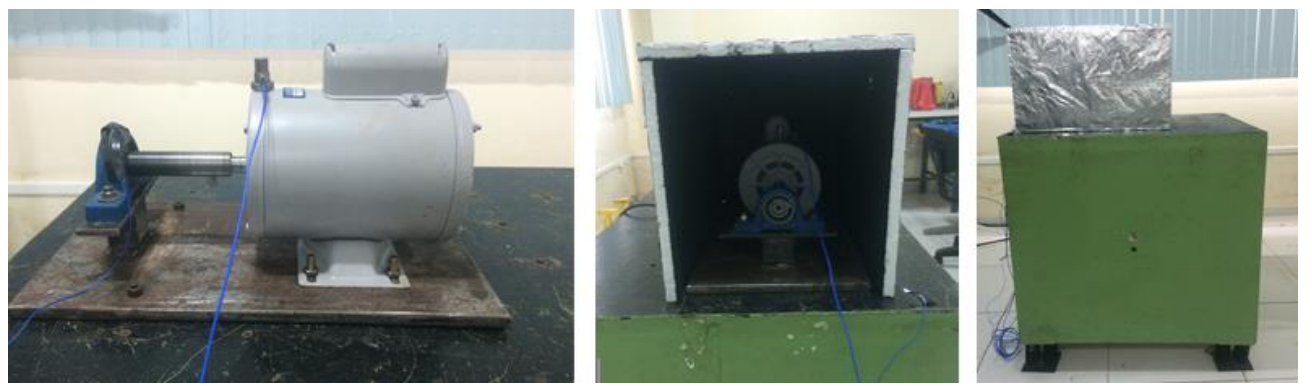

Fig. 3. Experimental apparatus.

It is worth noting that all the experiments were performed in the morning between 8:00 am and 12:00 pm, following the specifications of standards ABNT (Associação Brasileira de Normas Técnicas) NBRs 15718:2009; 15572:2013; 15572:2003; 16292:2014; 15424:2006. For the measurements of variables used to Ami probe 300 of Instrutemp and entered parameters for measurement are the emissivity, reflected temperature, ambient temperature, distance, relative humidity, air velocity and transmissivity for windows IR [10], [11]. All these parameters are shown in Tab. 1. The emissivity is considered one of the most important variables, because it is directly related to the temperature and the type of surface finish of the material. It is through it that realizes the heat emission of the object. For this work we adopted the emissivity $(\varepsilon)$ equal to 0.95 , due to the metal when heated tend to alter their thermomechanical properties.

Table. 1. Experiment data.

\begin{tabular}{|c|c|c|c|c|c|c|c|c|}
\hline Samples & $\begin{array}{c}\text { Failure } \\
\text { length } \\
(\mathrm{mm})\end{array}$ & $\varepsilon=$ & $\begin{array}{c}\Delta \mathrm{T} . \\
\text { Reflected } \\
\left({ }^{\circ} \mathrm{C}\right)\end{array}$ & $\begin{array}{c}\mathrm{T} . \\
\text { Environment } \\
\left({ }^{\circ} \mathrm{C}\right)\end{array}$ & $\begin{array}{l}\text { Distance } \\
(\mathrm{cm})\end{array}$ & $\begin{array}{c}\Delta \text { Relative } \\
\text { humidity. } \\
(\%)\end{array}$ & $\begin{array}{c}\text { Air } \\
\text { velocity } \\
(\mathrm{m} / \mathrm{s})\end{array}$ & $\begin{array}{c}\text { Window } \\
\text { transmissivity } \\
\left({ }^{\circ} \mathrm{C}\right)\end{array}$ \\
\hline B1 & 3,5 & \multirow{8}{*}{0,95} & 26,5 & 22 & \multirow{8}{*}{40} & 63,0 & \multirow{8}{*}{0,0} & 21 \\
\hline B2 & 3,0 & & 21 & 21 & & 63,0 & & 21 \\
\hline B3 & 2,0 & & 21 & 21 & & 53,0 & & 21 \\
\hline B4 & 1,0 & & 24,4 & 21,9 & & 54,4 & & 21 \\
\hline A1 & 3,5 & & 23 & 23,7 & & 48,8 & & 20 \\
\hline $\mathrm{A} 2$ & 3,0 & & 23,1 & 22 & & 54,9 & & 22 \\
\hline A3 & 2,0 & & 23 & 24,9 & & 47,2 & & 20 \\
\hline A4 & 1,0 & & 23,5 & 22 & & 53,0 & & 21 \\
\hline
\end{tabular}

The Table 1 It shows the parameters entered for the thermographic tests. As for the vibration analysis established the 10 second collection time interval, at an acquisition rate of $800 \mathrm{~Hz}$. The procedure was observed by means of the thermogram and confirmed by analyzing the occurrence of vibrations of the inserted failures. These, in turn, were observed from the frequencies $148.0 \mathrm{~Hz}$ with an amplitude of the inner races and the outer races $91.3 \mathrm{~Hz}$. See Fig.4.
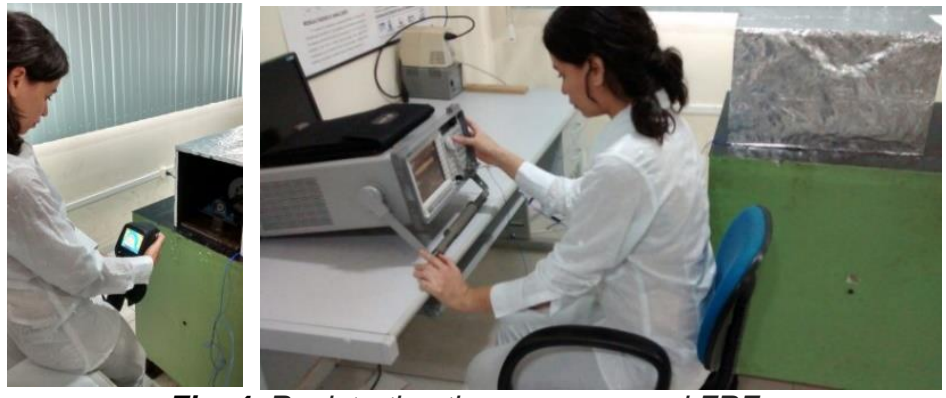

Fig. 4. Registration thermograms and FRF.

Before starting the analysis of vibration, first we used the hammer 086C03 model impact (impulse force test Hammer), in order to excite the experimental components (shaft and bearing) to accurately reproduce and measure the excitation force of system. The impact hammer has sensitivities ranging from 1 to $100 \mathrm{mV} / \mathrm{lbf}$ and masses from 0.1 to 5.5 $\mathrm{kg}$, with an amplitude range of up to $22 \mathrm{KN}$. The goal is to register via the data analyzer the natural frequency of the mechanical elements, see Fig.5. 

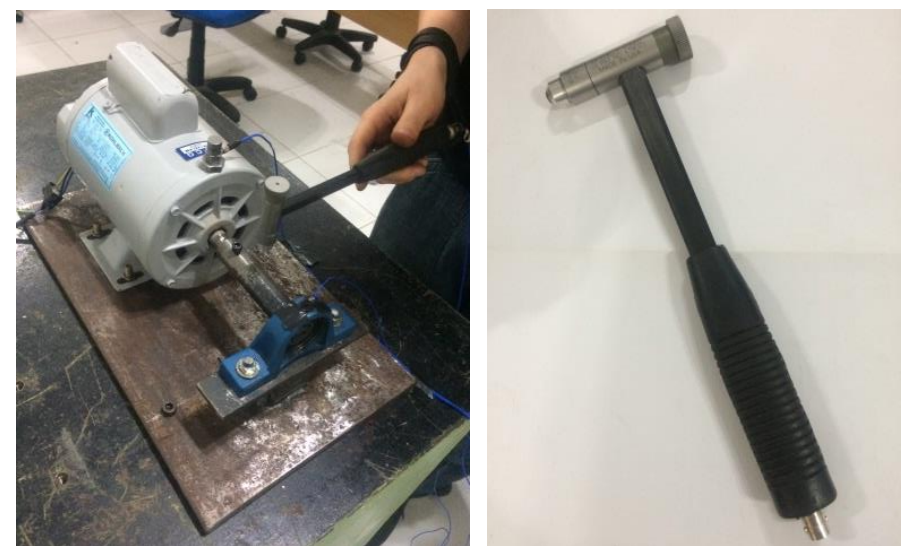

Fig. 5. Excitation System (left). Impulse force Hammer Test (right).

Vibration analysis procedures were based on Brazilian standards NBR 15928: 2011, 10272: 2013; 10273: 2013 ; 15928: 2011 and 10082: 2011. For the acquisition of data by selecting two points for the installation of sensors (accelerometers) model 352B10, model 352C68, namely motor and bearing, respectively. With accelerometers installed and connected to the analyzer dynamic signal-started the experimental tests. Every 5 minutes was recorded one track and a thermogram record. In all, seven track per sample and FRF at the end of each test.

Finally, the signal frequencies was treated in Matlab 13 and it built the following data acquisition graphs: signal in time; signal spectrum of the inner and outer races of the bearing; frequency (central resonance FFT) generating and envelope the Hilbert transform. For thermograms used the FLIR software.

\section{Results and discussion.}

Fig. 6 shows the thermograms obtained in two times laboratory test conducted at no load bearing. In this figure we highlight the so-called temperature measurement points: Sp1 and Sp2, featuring regions with inserted and defect free area defects, respectively. Observe also the measuring line (LI1) designed to determine the lower and higher temperature locations in the bearing under study.
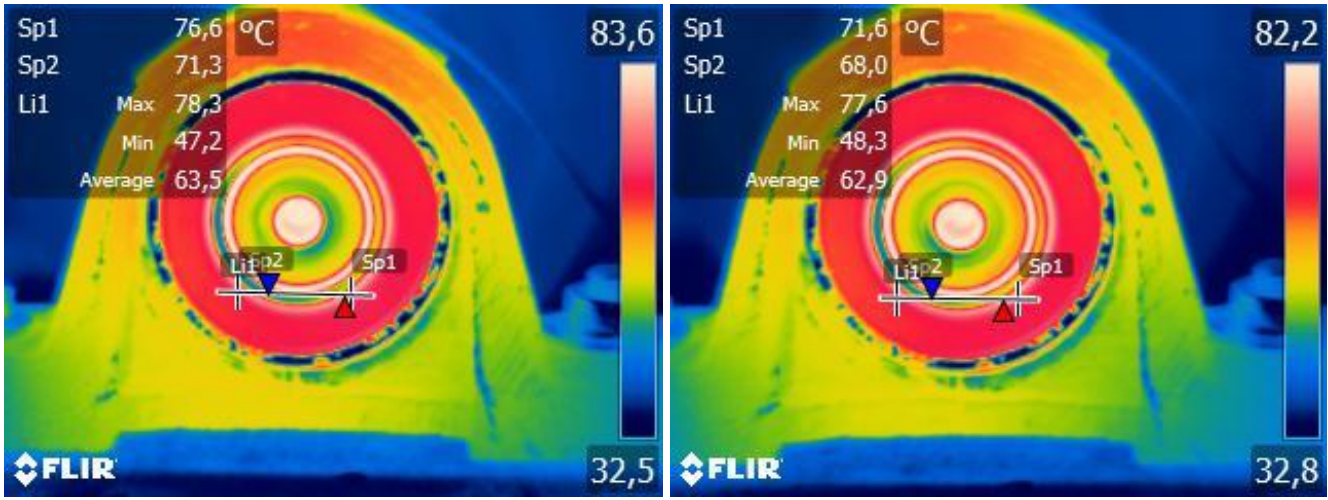

Fig. 6: The thermograms of Sample 1 (SP1 and SP2) respectively.

From this information and monitor the temperature at intervals of 5 minutes, the graphs are plotted, shown in Fig. 7 and 8. In the graph of Sample A, Sp1 zone (Zone defective inserted in the inner race) compared to Zone sp2 (defectfree Zone) perceive better temperature changes evidenced in the sample A1, A2, B1, B2. Over time, the thermal conduction process, the temperature will be distributed by the tracks of bearing and the bearing causing the temperature to drop and stabilize. The best results fault detection in these experiments were observed in twenty (20) first few minutes of operation of the equipment, that is, in the preheating phase the bearing.

Figure 7 depicts the temperature changes of samples of type A, between the sample $A 1$ and $A 4$, it is possible to realize the heating of the disparity in relation to the types of failures. For a monitoring laboratory, the sample $A 1$ stood out from the others due to the type and size of the fault. This was due to the accumulation of mechanical shock between failure on the track and rolling balls. 

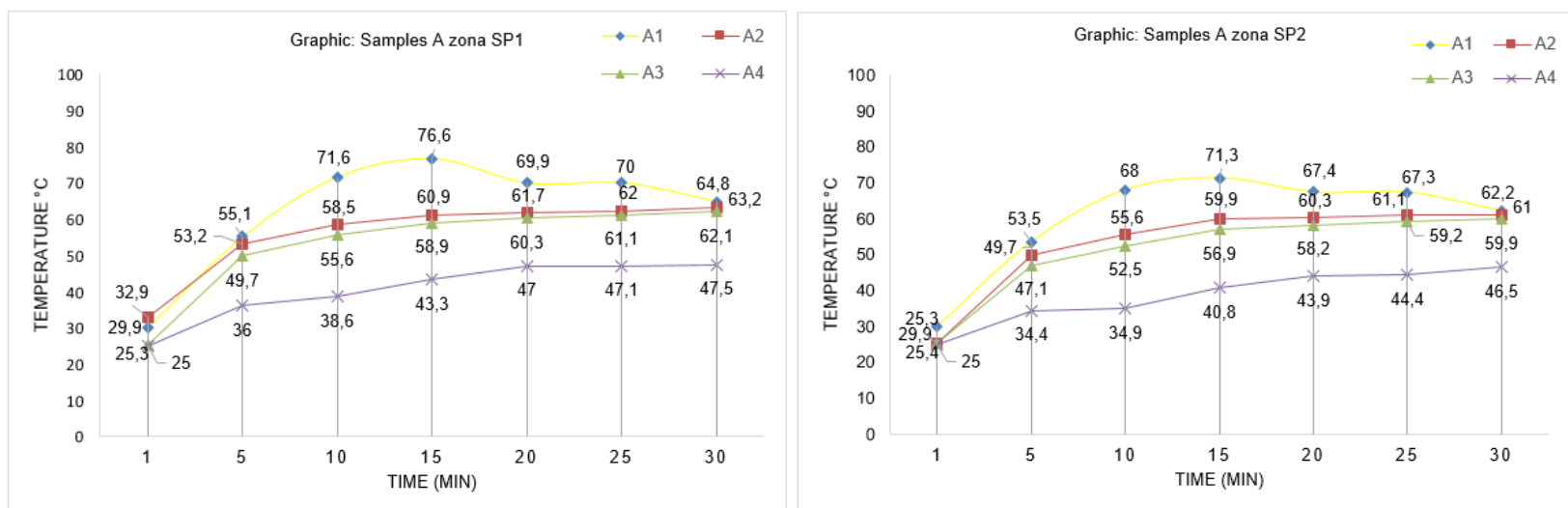

Fig. 7. Heating curves of sample A1, A2, A3, A4.

In samples of type B were not marked variations in the curves observed, but it was possible to sense temperature changes when compared to data from Sp1 Zone (Zone with insertion defects in outer race) with data from the Sp2 Zone (Zone free from defects ), see Fig. 8.
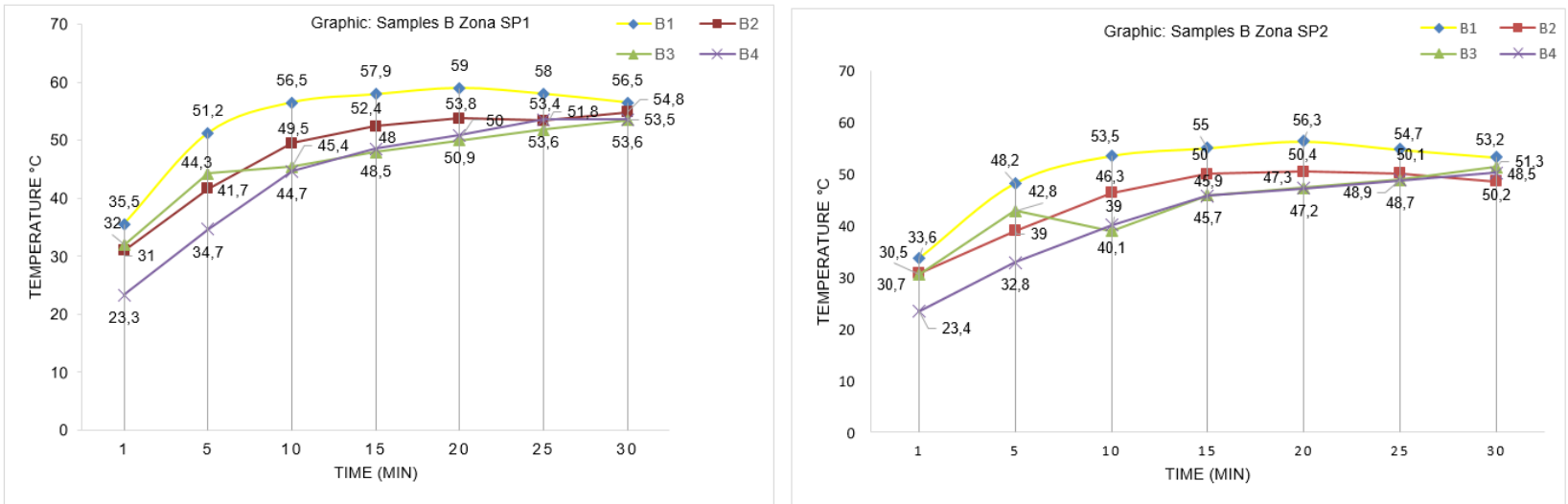

Fig. 8. Heating curves of sample $B 1, B 2, B 3, B 4$.

An important aspect to highlight regarding the differences between the heating curves shown in Fig. 7:08 concerns the size of the inserted fault and the path traversed by the rolling balls. Failure $1 \mathrm{~mm}$ (A4 and B4) allow the balls to pass over it without causing significant impact recording lower heating temperatures. Now, when the balls pass through failure $3.5 \mathrm{~mm}$ (A1 and $\mathrm{B} 1)$ record length is greater impacts translating in greater heating in the analysis region, see Fig. 9.
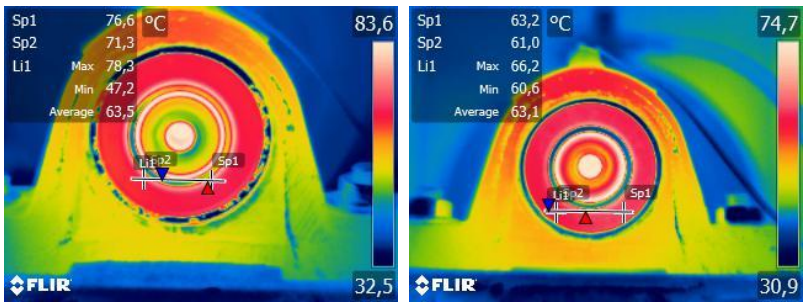

Fig. 9. Thermograms of samples $A 1, A 2, A 3$ e $A 4$.
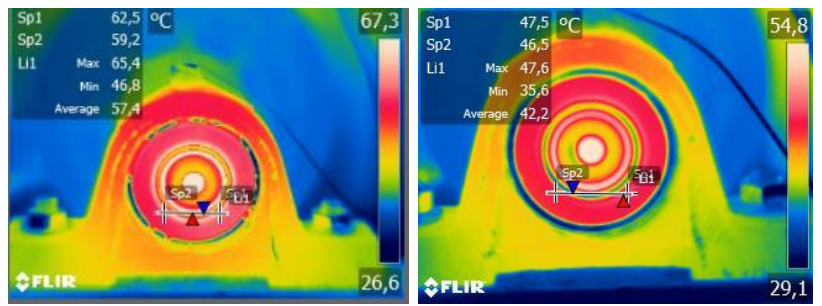

Both figures as Fig. 9 to Fig. 10 are shown the temperatures evidenced in thermographic records of the sample zones in SP1 and SP2. The thermograms are referred to the last moment of the experimental thermal record, followed by location and identification of failures and temperatures measured. 

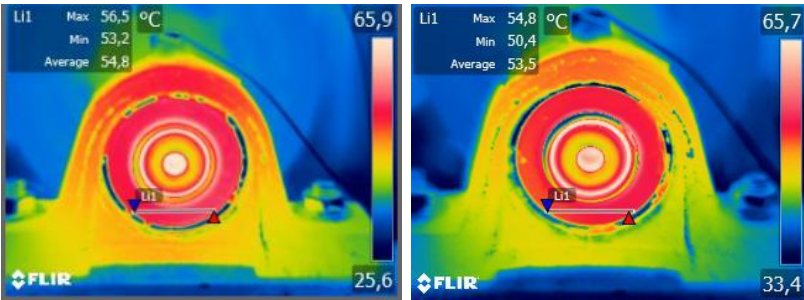

Fig. 1

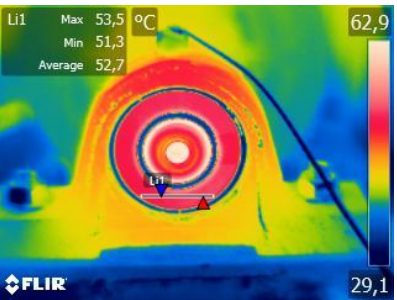

คFLIR

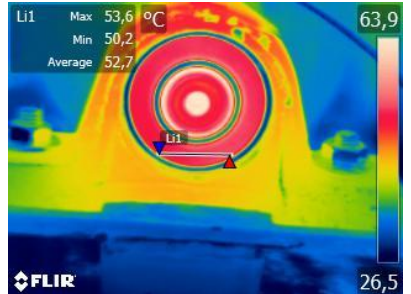

The graphs (Figs. 7 and 8 ) of heating curves show the variation of the studied areas temperature. As the fault is inserted on sp1 peaks up to $5.1^{\circ} \mathrm{C}$ in samples $\mathrm{A} 1, \mathrm{~A} 2, \mathrm{~A} 3$ and $\mathrm{A} 4$ recorded peaks of $3.1^{\circ} \mathrm{C}$, the samples $\mathrm{B} 1, \mathrm{~B} 2$ recorded maximum thermal variation of $3{ }^{\circ} \mathrm{C}$ and $2,7{ }^{\circ} \mathrm{C}$ on average for $\mathrm{B} 3$ and $\mathrm{B} 4$, as thermograms of $\mathrm{FIG}$. (s) 10 and 11 , demonstrate that these measurements the thermography as may assist in fault diagnostics.

However, it should be attentive to the fact compare, quantify and qualify the temperature of the rotating elements. Since, outdoors there are numerous interferences, and can make the thermographic reading difficult to identify the terms fault in bearing races by thermography. For the absence of proper manipulation of variables and attention to the type of surface analyzed impossible to acquire correct thermograms uncertainties and hence the heat emission of the machine element.

In addition to the heat emission, the bearing when defective also generates noise. Then use is made of vibration analysis. In the vibration spectrum, there is the presence of oscillatory peaks, these dynamic changes recorded in the frequency of $0 \mathrm{~Hz}$ to $800 \mathrm{~Hz}$, but for better signal analysis was restricted to $400 \mathrm{~Hz}$ (see Fig.11 e 12). The purpose was to confirm that the perceived failures by thermal radiation were real, and the vibration analysis also indicate defects.

In vibration analysis using the FFT, we sought the frequency range provided in the experiment. The FFT analyzes the inconstancy in the frequency range of peaks, as when a bearing is in perfect condition system arousal levels are constant, when this occurs there is no fault indications in the system and the use of envelopes (see Fig. (s) 13 and 14).

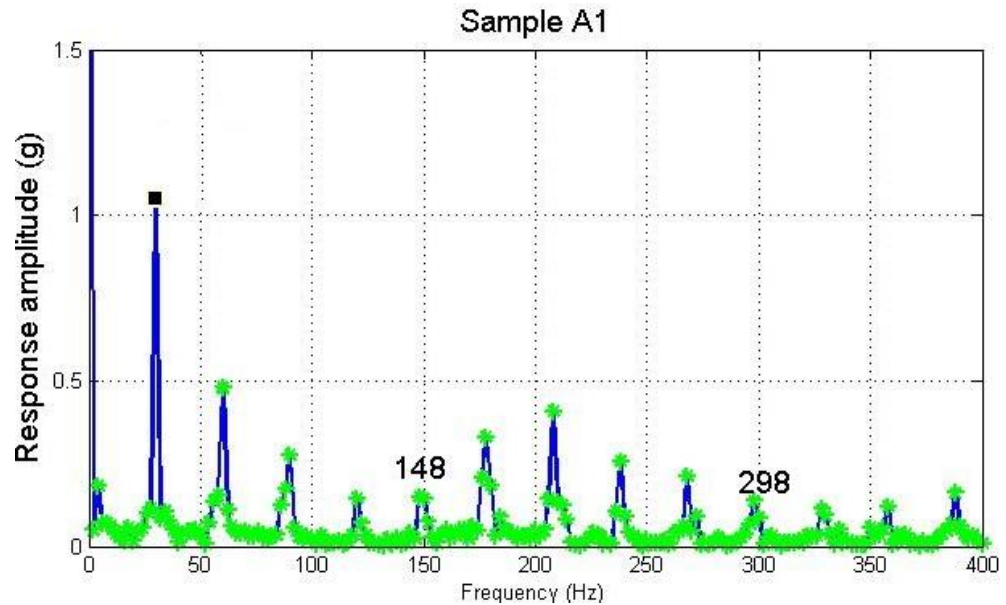

Fig. 11. Vibration spectrum Sample A1.

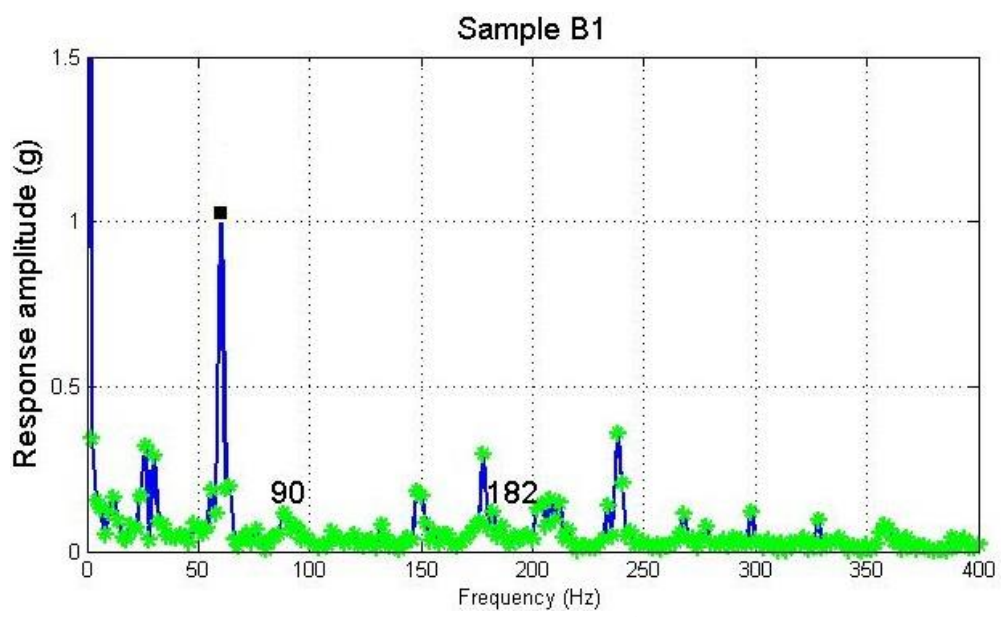

Fig. 11. Vibration spectrum Sample B1. 
In figure 11 and 12 presents the vibration spectra of samples A1 and B1 applying the FFT on these signals, we obtain the frequency spectra. Using the failure of equations in bearings for defects in the inner race and outer Eq.(1) and Eq. (2), We found some reference frequencies, the experimental test. To the inner race defects it was confirmed the expected ocilação of $148 \mathrm{~Hz}$, since the outer race to the expected frequency was $91,3 \mathrm{~Hz}$, and the experimental result was $90 \mathrm{~Hz}$, very close to the desired value. However, when considering a rotating element as the bearing, the periodicity, the resonance and the frequency amplitudes recorded in the FFT spectrum, they are decisive for the proof of fault on vibration analysis.

The envelope spectrum (Fig. 12 and 13) are all clearly visible harmonic DPFO, DPFI with spaced sidebands, which arise in the spectra due to a modulation of the signal. These sidebands ("sidebands") on the vibration signals arising defective bearings around a resonance frequency.
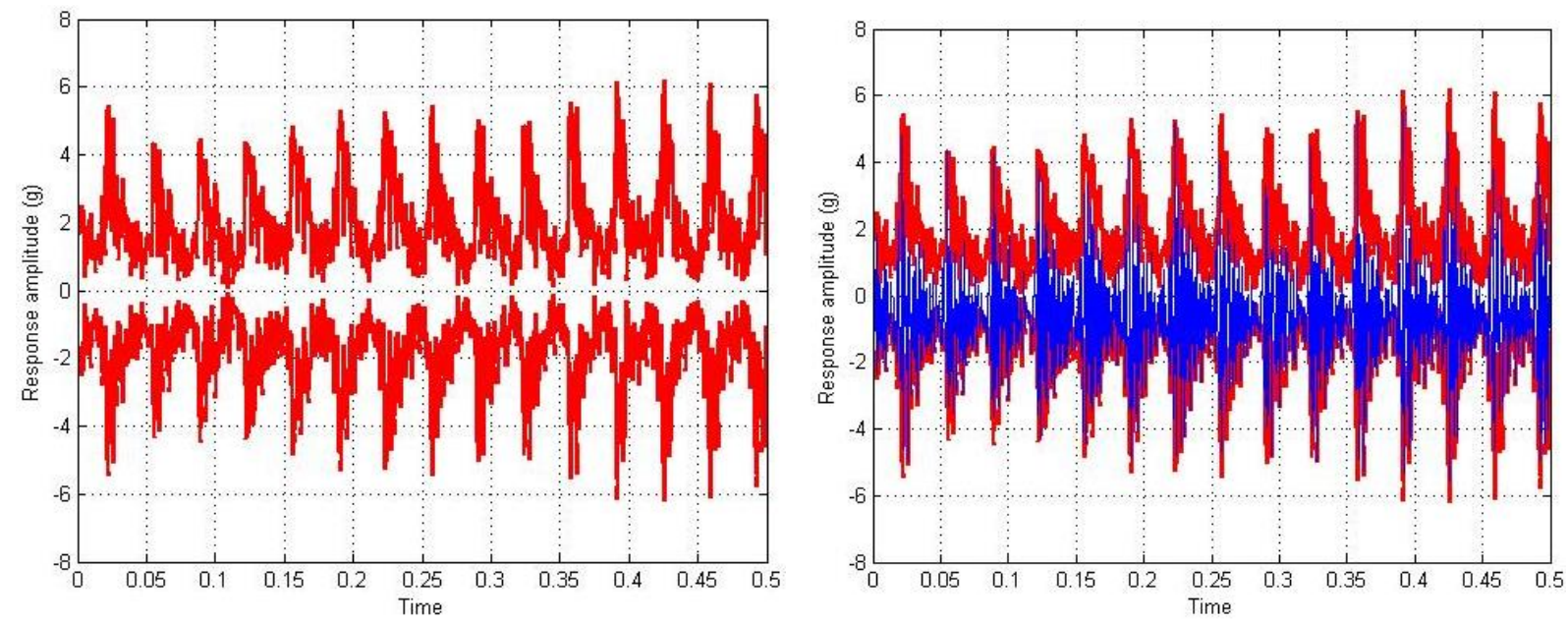

Fig. 13. Graphics on the envelope time A1.
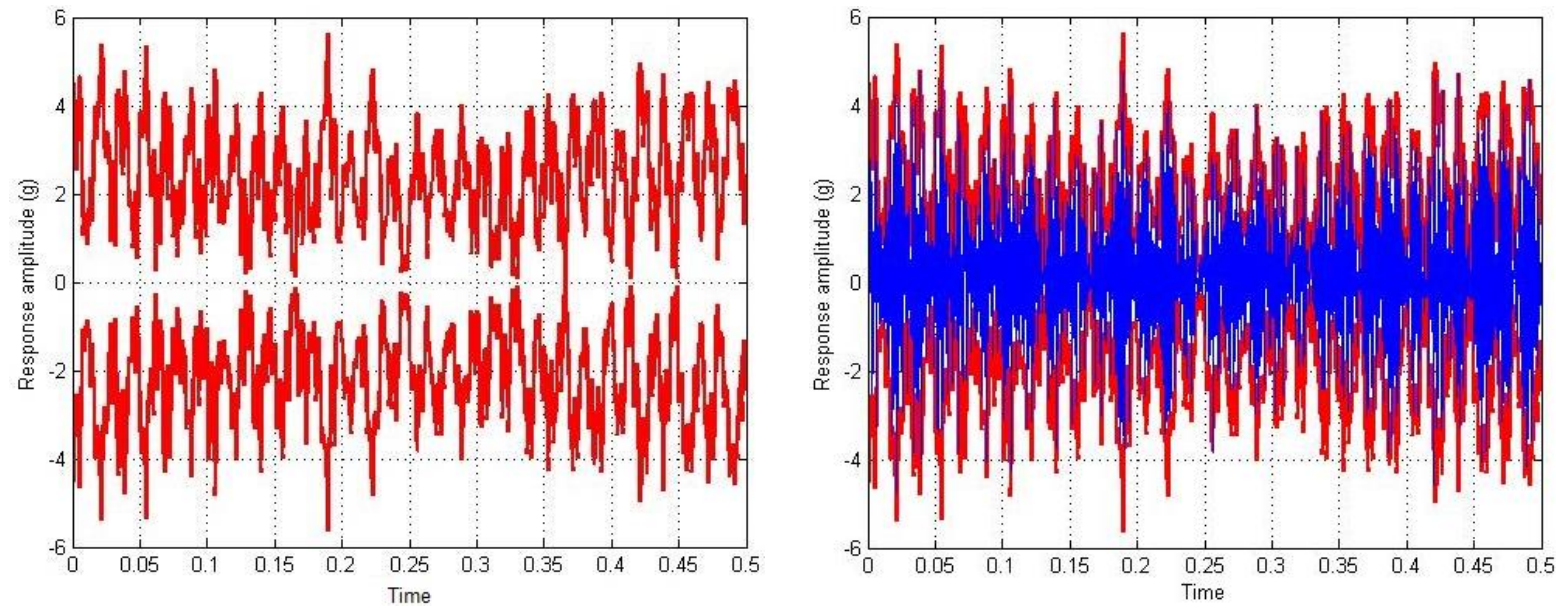

Fig. 14. Graphics on the envelope time B1.

Other A2 samples, A3, A4 and B2, B3, B4 have also been possible to identify changes in the vibration spectrum, but on the acquisition of data highlighted the samples $A 1$ and $B 1$, as they received higher thermal variation recorded in thermography. Faced with the above results it is possible to prove that thermography can assist in fault analysis diagnosis in rolling a ball career.

\section{Conclusions}

Given the results and conducted discussions we conclude that thermography can be used to help diagnose failures since the surfaces of the object are prepared, free from dust, grachas, oils and other parameters defined in the experiments can be manipulated during thermographic inspection. In contrary cases, the field, the data did not represent reliable quantitative information. In these cases, the use of other aid technique for diagnosing faults must be used to ensure the reliability of the results.

The study proves that thermography and a viable technique to qualify and quantify the flaws in the inner and outer bearing races, where it was possible to indicate the faulty areas and their thermal variation characterized in thermal analysis. Finally, the FFT shows frequency with respect to time of the amplitude peaks records in the defect area with the 
thermal information obtained in the vibration spectrum and enveloping signal. However, other tests involving thermography and analysis of rotary elements should also be investigated, such as; studies in the rolling balls, failures inner race and ball, flaws in the outer race and ball in cage. Finally, in all the elements of the bearing of an unshielded ball career.

\section{REFERENCES.}

[1] Amaro S. P. M. Cristiano. Melhoria de Produtividade na Operação e Manutenção de Máquinas de Fundição Injectada Sonafi, S.A. Cap. 3, pp. 37-46, Dissertação de Mestrado, FEUP. Porto, Portugal. jul. 2009.

[2] Affonso L. O. Amaral. Equipamentos mecânicos: Análise de falhas e solução de problemas. Cap. 1-3, pp 1-45. Rio de Janeiro, Qualitymark: Petrobras, 2002.

[3] Alegranzi B. Selvino. Construção e adequação de uma bancada de ensaio para investigações de técnicas não destrutivas de detecção de danos incipientes em rolamentos. Cap. 1-8, pp. 11-77. Tese de doutorado, UFRS, Porto Alegre, 2012.

[4] Almeira S. Antônio. Detecção e análise dinâmica de falhas em rolamentos. Cap. 1- 3, pp 4-5, 38-63. Tese de Doutorado, USP, São Carlos, São Paulo, 1999.

[5] Geitner k. Fred, Bloch P. Heinz. Análise e solução de falhas em sistemas mecânico. Cap. 3 e 5, pp 71-116, 333-362; Tradução Eduardo Kraszczuk. Ed. 1 ${ }^{\circ}$ Rio de Janeiro. Elsevier, 2015.

[6] Caramalho Alberto. 25 anos em termografia. Cap. 7-8, pp 67-87. Ed. 1º, Portugal, 2012.

[7] Ahmadipour, Foroughi, Nematollahi, SotoudehBahreini, Detection of Pillow Block Bearings Defect Using Infrared Thermography: A Case Study in Golgohar Mining and Industrial Co. Quantitative InfraRed Thermography Journal, pp 1-7, 2015.

[8] Pacholok, M. Uso da termografia para avaliação do desalinhamento de máquinas rotativas: uma ferramenta auxiliar à análise de vibrações. Dissertação de Mestrado, PUC- PR, 2004.

[9] Sobrinho M. Pedro, Mathias M. Hugo, Souza G. S. Victor. Methodology for failure analysis integrating of vibration analysis and themography. Cobem, 2015. Rio de Janeiro, 2015.

[10] Chrzanowski Krzysztof. NON-CONTACT THERMOMETRY Measurement Errors. Cap. 2, pp 31-40. SPIE Polish Chapter, Warsaw, Ed.7, Poland, 2001.

[11] Minkina Waldemar; Dudzik Sebastian. Infrared Thermography Errors and Uncertainties. Cap. 1-2,pp, 1-29, Ed. John Wiley \& Sons. Czestochowa, University of Technology, Poland. 2009.

[12] Andrade, Alan Sulato. Elementos orgânicos de máquinas ii at-102. Universidade Federal do Paraná Curso de Engenharia Industrial Madeireira. Paraná, 2015.

[13] Incropera, F. P e Dewitt, D. P. Fundamentals of Heat and Mass Transfer. Cap. 12, pp. 495-521, 5a Edição, ed. Copyrights, John Wiley \& Sons, 2002.

[14] Harris, T. A.; Kotzalas, M. N. Essential Concepts of Bearing Technology, Fifth Edition. Cap. 11, pp.195 - 249. Ed. 5; Taylon \& Francis, London, New York; 2007.

[15] Smith, William F. e Hashemi, Javad. Fundamentos de Engenharia e Ciência dos Materiais. Cap. 6-9, pp. 149260. Ed.5․ São Paulo, SP. 2012.

[16] Weidlich, Felipe. Avaliação de lubrificação de rolamentos de motores elétricos por ultrassom. Cap. 3, pp. 46-51. Dissertação de Mestrado. Universidade Federal do Rio Grande do Sul. UFRGS. Porto Alegre, RS; 2009.

[17] NSK. Novas tecnologias: Soluções inteligentes. p. 7 - 8. Catálogo NSK. São Paulo. SP.

[18] Mazioud A, Ibos L, Khlaifi A, Durastanti J.F., "Detection of rolling bearing degradation using infrared Thermography".9th International Conference on Quantitative Infrared Thermography, July 2-5, 2008, Krakow Poland.

[19] SKF. High temperature Bearings For operating temperatures up to $350{ }^{\circ} \mathrm{C}\left(660^{\circ} \mathrm{F}\right)$. pp. 7-9. PUB BU/P2 14961 EN, SKF Group, December, 2014. 